\title{
Deficiency of coagulation factor VII in a 4 years old child with $13 q$ deletion syndrome: a case report
}

\begin{abstract}
Background: Factor VII deficiency is rare inherited bleeding disorders, have been identified in the Factor VII gene located on chromosome 13 with very few cases reported. Factor VII deficiency was first described by Alexander et al. in 1951.The disorder has also been known as Alexander's disease. It is the rare inherited bleeding disorders' with an estimated incidence of 1 case per 3,00,000 to 5,00,000 individuals.
\end{abstract}

Objective and method: We did a case report and literature review for deficiency of coagulation factors VII was found in a 4 years patient who had chromosomal aberration 13q deletion syndrome (46, XX, del 13q32-13q33). This loci involved in synthesis or constitution of factor VII.

Results: A review of the gene map of chromosome 13 indicated that Factors VII and X are coded on the long arm of chromosome 13, within the deleted region.

Conclusion: Congenital Factor VII deficiency is a rare cause of bleeding disorder, which should be suspected in a bleeding child presenting in infancy when platelets and aPTT are normal with abnormal PT. Congenital Factor VII deficiency association with 46, XX, del $(13 q 32-13 q 33)$ syndrome is very rare disorder and further cases should be reported to know the outcome and the risk of complication in such a cases.

Keywords: 13q deletion syndrome, factor VII deficiency, factor 7 deficiency, partial monosomy of the long arm of chromosome 13, factor VII
Volume 9 Issue I - 202 I

\author{
Housam AL Madani, Soltan Hassan, Ghada \\ Ajwa, Basel Dahlawi \\ Department of Pediatric, King Fahd Armed Forces Hospital \\ (KFAFH), Saudi Arabia
}

\author{
Correspondence: Housam AL Madani, Department of \\ Pediatric, King Fahd Armed Forces Hospital (KFAFH), Saudi \\ Arabia, 7393 Al-Bathaa, Al Faisaliah dist, Apartment 7, Jeddah \\ 23442 - 2526, Saudi Arabia, Tel 966504685495 , \\ Email Dr_housam_almadani@hotmail.com
}

Received: January 19, 2021 | Published: January 25, 2021

\section{Introduction}

Factor VII deficiency is rare inherited bleeding disorders, have been identified in the Factor VII gene located on chromosome 13 with very few cases reported. ${ }^{1,2}$ Factor VII deficiency was first described by Alexander et al. in 1951. ${ }^{3}$ The disorder has also been known as Alexander's disease. It is the rare inherited bleeding disorders' with an estimated incidence of 1 case per 3,00,000 to 5,00,000 individuals. ${ }^{4}$ Factor VII deficiency can be acquired during life; this report deals with the genetic form, which is present at birth (although symptoms may develop later).

\section{Case presentation}

A 4 year-old female presented with factor VII deficiency and $13 \mathrm{q}$ deletion syndrome. She was the first child of a 30 -year-old mother with no history of miscarriage and 29 year- old father with a second-degree consanguinity. This pregnancy was complicated by premature rupture of membrane for 36 hours prior $\mathrm{C}$ section due to oligohydramnios.

She was born at 37 weeks of gestational. Her birth weight was $2.1 \mathrm{~kg}$ ( $<10$ th centile), height $46 \mathrm{~cm}$ (10th centile), head circumference 29.5 $\mathrm{cm}$ (10th centile) and Apgar scores were 9 and 9 at 1 and 5 minutes, respectively. At birth, she was noted to have facial dysmorphism, microcephaly and anterior anus displacement, so referred for genetics work-up, including karyotype revealed a deletion of chromosome 13(46, XX, del 13q32-13q33). Both an echocardiogram and a renal ultrasound showed ASD 3-5 mm with a left to right shunt and bilateral hydronephrosis and pelvictasia, respectively.

A generalized seizures had been developed at the age of 3 years, however brain MRI showed that the ventricular system appears slightly prominent with clear visualization of CSF spaces, but EEG revealed sub cortical epilepsy with right-brain predominance that have been successfully managed with antiepileptic medication. As part of her pre-operative work-up for dental abscess, she was discovered to have elevated Prothrombin $19.6 \mathrm{sec}$, so referred to pediatric hematology clinic for further assessment and the mother endorsed history of epistaxis twice per month in last two months that not require medical treatment and stopped spontaneously, but there was no family history of bleeding disorders or history of bleeding from other mucosal surfaces such as gum bleeding, hematuria, hematochezia, melena , swelling in joints, and spontaneous skin bruising.

On physical examination, the patient's height is $108 \mathrm{~cm}$ (50th centile), his weight is $17 \mathrm{~kg}$ (50th centile) and his head circumference is $43 \mathrm{~cm}$ ( $3 \mathrm{rd}$ centile). She has dysmorphic features microcephaly, broad nasal bridge and micrognathia. Her skin shows no ecchymosis or petechiae. His ears are normally placed without tags or pits. Her palate and uvula are normal without petechiae. She has normal heart rate, rhythm regular with grade 2 ejection systolic murmur audible over the left 2nd \&3rd intercostals space .her lung, abdominal, back and rectal examination are unremarkable. Her neurological examination shows developmental delay, intellectual disability, behavioral problems, microcephaly, mild hypotonia, normal reflexes and walk incoordination.

Laboratory investigations demonstrated hemoglobin $80 \mathrm{~g} / \mathrm{L}$ and platelet count $596 \times 10^{9} / \mathrm{L}$. Liver and kidney function tests were normal; however, the Prothrombin time (PT) was prolonged $19.6 \mathrm{sec}(12.6$ $-14.61 \mathrm{sec}$ ). The activated partial thromboplastin time (APTT) was $39.2 \mathrm{sec}$ (normal range, 29.9 - $40.3 \mathrm{sec}$ ). Then Factor VII deficiency ( $24 \%$ of normal) was subsequently diagnosed after factor assays were done and summarized in table 1 and 2 below. 
Table I Summary of coagulation studies and factor levels in patients

\begin{tabular}{lll}
\hline & Patient result & Normal range \\
\hline Prothrombin time (PT) & $19.6 \mathrm{sec}$ & $(12.6-14.6 \mathrm{I} \mathrm{sec})$. \\
The activated partial thromboplastin time (APTT) & $39.2 \mathrm{sec}$ & $(29.98-40.39 \mathrm{sec})$. \\
International Normalized Ratio (INR) & 1.5 & $(0.9-1.15)$ \\
Fibrinogen & $272 \mathrm{mg} / \mathrm{dl}$ & $(207.14-4 \mid 7.14)$ \\
Factor VII & $10 \mathrm{w} 24 \%$ & $(60-150)$ \\
Factor X & $107 \%$ & $(60-150)$ \\
Von will brand antigens & $83 \%$ & $(70-130)$ \\
Von will brand factors RCO & $81 \%$ & $(50-200)$ \\
\hline
\end{tabular}

Table 2 Summary of factor levels in the patient and her parents

\begin{tabular}{llllll}
\hline & \multicolumn{2}{l}{ Patient } & \multicolumn{2}{l}{ Father } & Mother \\
\hline Factor VII & $24 \% \quad$ (low) & $1 \mathrm{I} 2 \%$ & (normal) & $89 \%$ (normal) \\
Factor $X$ & $95 \%$ (normal) & $117 \%$ & (normal) & $91 \%$ (normal) \\
\hline
\end{tabular}

Chromosome karyotyping was performed for the patient and her parents showed 13q deletion syndrome (karyotype 46, XX, del(13q32$13 \mathrm{q} 33$ ) on the long arm of one chromosome 13, father was a carrier for balanced translocation of chromosome $13 \& 8$ at the $\mathrm{q}$ arm and the mother's chromosome was normal, respectively.

A review of the gene map of chromosome 13 indicated that Factors VII and X are coded on the long arm of chromosome 13, within the deleted region. Functional Factor VII and X assays were performed for the patient and her parents. The index case demonstrated a Factor X level of $95 \%$ and a Factor VII level of only $24 \%$. Factor VII deficiency was diagnosed. Maternal results were $91 \%$ (Factor X) and $89 \%$ (Factor VII), and paternal results were $117 \%$ (Factor X) and $112 \%$ (Factor VII).

\section{Discussion}

A review of the gene map of chromosome 13 indicated that Factors VII and X are coded on the long arm of chromosome 13, within the deleted region. ${ }^{5}$ Pfeiffer ${ }^{6}$ described two cases of $13 \mathrm{q}$ terminal deletion with associated subclinical deficiency of Factors VII and X (in each case activity of these factors was around $50 \%$ of the normal value). The genes for Factors VII and X were subsequently mapped to13q34 by Gilgenkrantz et al. It is probable that patients with $13 \mathrm{q}$ deletion syndromes involving the Factor VII region have a greatly increased rate of Factor VII deficiency compared to the general population, with a rate of Factor VII deficiency approximating the background frequency of the heterozygous or carrier state. Hewson and Carter described severe Factor VII deficiency in a case of 13q deletion syndrome. ${ }^{7}$ Our patient factor Vll deficiency that manifested as elevated PT, would be 13q32-33 ( similar case is present in letterature: Balci S, et all, Genet Couns, 2010;21(3):317-312. ${ }^{8}$

Clinical bleeding can widely vary and does not always correlate with the level of FVII coagulant activity measured in plasma. Mortality is related to severe bleeding, most often resulting from CNS hemorrhage. Most severe cases of FVII deficiency are diagnosed during childhood, often during the first 6 months of life. In infancy, the most common bleeds occur in the gastrointestinal tract or CNS, accounting for $60-70 \%$ of bleeds in this age grou. ${ }^{9,10}$
The PT is prolonged in FVII deficiency and the INR is elevated. The aPTT is within the reference range in isolated FVII deficiency as seen in the index case. FVII assays are performed by using thromboplastin-dependent one-stage clotting assay. The more sensitive thromboplastins, usually recombinant human thromboplastin, are preferred for measuring FVII activity in the very low range.

\section{Conclusion}

Congenital Factor VII deficiency is a rare cause of bleeding disorder, which should be suspected in a bleeding child presenting in infancy when platelets and aPTT are normal with abnormal PT. Congenital Factor VII deficiency association with 46, XX, del (13q32-13q33) syndrome is very rare disorder and further cases should be reported to know the outcome and the risk of complication in such a cases.

\section{Conflicts of interest}

The authors have no conflicts of interest to declare. All co-authors have seen and agree with the contents of the manuscript and there is no financial interest to report.

\section{Acknowledgments}

None.

\section{Addendum}

All authors contributed to data collection, literature review and writing the paper.

\section{References}

1. Cooper DN, Millar DS, Wacey A, et al. Inherited factor VII deficiency: molecular genetics and pathophysiology. Thromb Haemost. 1997;78(1):151-160.

2. Mariani G, LoCoco L, Bernadi F, et al. Molecular and clinical aspects of factor VII deficiency. Blood Coag Fibrinol. 1998;9(Suppl 1):S83-S88.

3. Alexander B, Goldstein R, Landwehr G, et al. Congenital SPCA deficiency: a hitherto unrecognised coagulation defect with haemorrhage rectified by serum, serum fractions. J Clin Invest. 1951;30(6):956.

4. Peyvandi F, Mannucci PM. Rare coagulation dis - orders. Thromb Haemost. 1999;82(4):1207-1214.

5. Gilgenkrantz S, Briquel ME, Andre E, et al. Structural genes of coagulation factors VII and X located on 13q34. Ann Genet. 1986;29(1):32-35. 
6. Pfeiffer RA, Ott R, Gilgenkrantz S, et al. Deficiency of coagulation factors VII and X associated with deletion of a chromosome 13 (q34): evidence from two cases with 46,XY,t(13;Y) (q11;q34). Hum Genet. 1982;62(4):358-360.

7. Mariani G, Dolce A, Marchetti G. Clinical picture and management of congenital factor VII deficiency. Hemophilia. 2004;10(Suppl 4):180-183.

8. Ingerslev J, Kristensen L. Clinical picture and treatment strategies in factor VII deficiency. Hemophilia. 1998;4(4):689-696.
9. Hewson MP, Carter JM. Severe congenital Factor VII deficiency associated with the 13q deletion syndrome. Am J Hematol. 2002;71:232-233.

10. S Balci, B Yuksel Konuk, F Atik, et al. Partial deletion of the long arm of chromosome 13 (q32q33.2) associated with mental retardation, choanal atresia and fish mouth. Genet Couns. 2010;21(3):317-324. 